\title{
VIOLÊNCIA CONTRA AS MULHERES E A MEDIAÇÃO DO/A BIBLIOTECÁRIO/A - CENTRO ESTADUAL DE REFERÊNCIA DA MULHER FÁTIMA LOPES
}

\author{
Maria Cristiana Felix Luciano \\ Graduada em Biblioteconomia \\ cristiana2012.felix@gmail.com \\ Gisele Rocha Côrtes \\ Doutora em Ciências Sociais \\ Professora do DCI/PPGCI - UFPB \\ giselerochacortes@gmail.com
}

Resumo

\begin{abstract}
A violência doméstica, que atinge mulheres cotidianamente, constitui um problema social e uma violação dos direitos humanos. A ausência de informações oficiais a respeito da dinâmica das violências e o perfil das mulheres recebidas em órgãos de atendimento configuram-se como um desafio no planejamento de políticas públicas condizentes com as necessidades das mulheres. Considerando que o acesso à informação pode contribuir para a redução da violência e para a produção de novos conhecimentos, essa proposta objetiva apresentar o Centro Estadual de Referência da Mulher Fátima Lopes/Campina Grande (CERMFL), órgão de atendimento específico às mulheres em situação de violência. $\mathrm{O}$ trabalho mapeia o perfil das mulheres, com foco na: faixa etária, caracterização étnico-racial, situação conjugal, renda, cidade, relação com o/a autor/a da violência, local de ocorrência, e tipo de violência sofrida. De tipo descritiva e abordagem quantitativa, a pesquisa utilizou-se de fontes documentais, mais especificamente, as fichas de atendimento do ano de 2015. Para a análise dos dados, lançou-se mão da estatística descritiva. Por meio das informações estatísticas produzidas, verifica-se que a violência contra mulheres demanda ações intersetoriais para o fortalecimento das mulheres e o rompimento com a situação de violência. Constatase que o tratamento, a produção e a disseminação de informações estatísticas oficiais são indispensáveis para o aprimoramento das políticas públicas voltadas para a prevenção e a erradicação da violência e da violação dos direitos humanos.
\end{abstract}

Palavras-chave: Violência doméstica. Informação. Centro de Referência da Mulher. Mediação da Informação. Relações de Gênero.

\section{INTRODUÇÃO}

A violência é um fenômeno complexo e multifacetado, que atinge mulheres de todas as classes sociais, grupos étnico-raciais, nacionalidades, faixas etárias e graus de escolaridade. Segundo Teles e Melo (2003) a violência contra as mulheres é qualquer ato direcionado às mulheres que venha ferir a sua integridade humana causando danos físicos, psicológicos, morais, sexuais ou patrimoniais. ${ }^{1}$

\footnotetext{
${ }^{1}$ A Lei Maria da Penha, LEI No 11.340 , tipifica os tipos de violência contra a mulher. Diponível em: http://www.planalto.gov.br/ccivil_03/_ato20042006/2006/lei/111340.htm
}

A Agência Europeia de Direitos Fundamentais (FRA) aponta que uma em cada três mulheres, na União Europeia (EU), foi vítima de violência física, ou sexual, ao menos uma vez sua vida desde os 15 anos. O estudo se baseia nos testemunhos de 42 mil mulheres de 18 a 74 anos, coletados nos 28 países da UE em entrevistas individuais entre março e setembro de 2012. No Brasil, a pesquisa intitulada Mapa da violência 2015, aponta que o país ocupa a quinta posição na incidência de 
homicídios de mulheres, num ranking mundial de 83 países $^{2}$. No Brasil, há uma legislação especifica a respeito da violência doméstica, a Lei 11.340/2006, Lei Maria da Penha. No artigo 8, a lei apresenta como prerrogativa que estados e municípios promovam estudos e pesquisas para produzir e sistematizar dados (com a perspectiva de gênero e raça/etnia) referentes à dinâmica da violência doméstica e familiar contra as mulheres. Contudo, desafios ao seu cumprimento persistem, ocasionando dificuldades para a obtenção de informações oficiais confiáveis. Estudos apontam a carência de dados estatísticos oficiais como um entrave para a prevenção e a coibição da violência contra as mulheres (PANORAMA..., 2016).

Campos e Almeida (2017, p. 362) destacam:

A relevância das estatísticas sistemáticas e informações oficiais na cobertura de casos de violência contra mulheres para que possam ter visibilidade, bem como alguns percalços que podem ser encontrados. A implementação destes sistemas pode não só propiciar a formulação de novos indicadores, como subsidiar e aprimorar o planejamento de ações para o enfrentamento da violência contra as mulheres.

No Brasil, estudos acadêmicos e a militância feminista em diferentes perspectivas, desde a década de 80, entendem ser imprescindível a compreensão do fenômeno da violência contra as mulheres pelo prisma das relações de gênero. Problematizam que as várias configurações das agressões, como a violência física, psicológica, sexual, moral e patrimonial não se justificam pela naturalização de comportamentos de homens e mulheres, mas devem ser analisadas tendo como alicerce as relações de poder. Neste sentido, surge o conceito relações de gênero, que parte da construção social das masculinidades e feminilidades em diversos contextos históricos, sociais e culturais (LOURO, 1996). Para o estabelecimento de relações de gênero igualitárias, faz-se necessário desconstruir padrões hierárquicos

\footnotetext{
${ }^{2}$ El Salvador, Colômbia, Guatemala, Federação Rússia, sucessivamente ocupam as primeiras colocações no índice de violência. Disponível em: https://www.mapadaviolencia.org.br/pdf2015/MapaViolencia_2015_mulheres.pdf
}

que alocam as mulheres em situações de desigualdade no mercado de trabalho, na participação política, no acesso à educação, na mercantilização do seu corpo, e no meio científico. Como afirma Lauretis (1994,p. 209),"a construção do gênero também se faz por meio de sua desconstrução".

Com base nas questões acima mencionadas, o objetivo geral deste artigo se configura assim: apresentar o Centro Estadual de Referência da Mulher Fátima Lopes/Campina Grande, equipamento da política pública do programa de enfrentamento e prevenção à violência contra mulheres. Especificamente, pretendemos apresentar os atendimentos oferecidos pelo CERMFL e o perfil das mulheres atendidas. ${ }^{3}$

$\mathrm{O}$ acesso e o controle de recursos materiais e informacionais, de acordo com configuramse como mecanismos de empoderamento das mulheres. A informação estimula a construção da autonomia, da auto-confiança e da autoestima, instrumentos necessários para que as mulheres, individual e coletivamente, possam atuar no sentido de transformar as estruturas sociais de classe, gênero, raça, e orientação sexual, dentre outras. Nesta perspectiva, o campo da CI pode fortalecer a redução das desigualdades por meio da atuação da/o bibliotecária/o como mediadora/or no tratamento, disseminação e publicização de conteúdos informacionais atinentes a políticas públicas de enfrentamento da problemática.

\section{VIOLÊNCIA CONTRA AS MUL- HERES E RELAÇÕES DE GÊNERO}

No Brasil, uma pesquisa realizada por Waiselfisz (2015, p.27) mostrou que, em relação à violência contra mulheres, o Brasil apresenta números alarmantes. Segundo a pesquisa,

Entre 1980 e 2010 foram assassinadas mais de 92 mil mulheres no Brasil, 43,7 mil somente na última década, passando de 2,3 para 4,6 homicídios. Apenas em 2011 mais de 4,5 mil mulheres foram assassinadas no país. Dados e estatísticas sobre violência contra as mulheres mostram que $80,26 \%$ das mulheres

\footnotetext{
${ }^{3} \mathrm{O}$ artigo decorre de Trabalho de Conclusão de Curso de Graduação em Biblioteconomia.
} 
vítimas de violência tinham relações afetivas com o agressor.

No ponto de vista de Odalia (1991) a violência não é evidente por si mesma em todas as suas manifestações, pois algumas são tão sutis que podem não ser reconhecidas. A violência psicológica, por exemplo, acontece das mais diversas formas e o mais agravante é que em muitos casos a própria vítima não se reconhece em situação de violência. Em geral, a violência doméstica contra mulheres, ocorre em contexto de profundas desigualdades de gênero na sociedade. $\mathrm{O}$ termo relações de gênero aborda as diferenças construídas socialmente entre mulheres e homens. Louro (1997, p.22) enuncia que:

Não há, contudo, a pretensão de negar que o gênero se constitui com ou sobre corpos sexuados, ou seja, não é negada a biologia. O conceito pretende se referir ao modo como as características sexuais são compreendidas e representadas.

Gênero, portanto, é um termo utilizado para dar significado à construção dos sujeitos. $\mathrm{Na}$ concepção de Scott (1990, p.14), "o gênero é um elemento constitutivo de relações sociais fundadas sobre as diferenças percebidas entre os sexos, é um modo primordial de dar significado às relações de poder [...]". A partir da compreensão sobre gênero,é possível criar mecanismos informacionais que possibilitem uma compreensão aprofundada do fenômeno da violência contra mulheres. Deste modo, o que se pretende por meio deste conceito é desnaturalizar comportamentos e representações, além de dar visibilidade às diferenças socialmente construídas e à maneira como estas diferenças têm se convertido em desigualdades, em especial para as mulheres.

Os estudos de gênero vêm, aos poucos, construindo uma nova mentalidade nos meios informacionais. Eles oferecem os instrumentos de análise de como (e para quem) a

\footnotetext{
${ }^{4}$ Segundo o Instituto Patrícia Galvão, atualmente existem 500 Delegacias Especializadas de Atendimento à Mulher, 160 núcleos especializados no âmbito de distritos policiais comuns, 235 centros de referência especializados, 72 casas abrigo, 92 juizados-varas especializadas em violência doméstica, 59 núcleos especializados na Defensoria
}

participação das mulheres se torna componente de mudança da realidade e se configura como parte da história (CRIPPA, 2011).

\section{BREVE HISTÓRICO DA IM- PLANTAÇÃO DE ÓRGÃOS DE ATENDIMENTO ÀS MULHERES EM SITUAÇÃO DE VIOLÊNCIA - CEN- TROS DE REFERÊNCIA DA MULHER}

Os movimentos feministas e de mulheres foram protagonistas no enfrentamento à violência contra mulheres no Brasil, na década de 1970. Segundo Matos (2015, p. 150) "o feminismo pode ser considerado um movimento social, uma campo de producão de conhecimento fortemente teorizado e disputado e mesmo uma visão emancipatória de mundo." A autora afima que o feminismo colocou as mulheres no centro do debate politico e científico da modernidade, visibilizando sua constituição como sujeitos e objetos da análise. Destaca, ainda, que o feminismo apresenta gramáticas distintas a respeito dos processos de emancipaçao das mulheres, desta forma, explicita a existência de muitos feminismos.

Por meio de protestos, manifestações, e campanhas, esses grupos pautaram, em diversos governos em âmbito federal, estadual e municipal, a necessidade de implantação de políticas específicas para as mulheres em situação de violência doméstica. No entanto, ainda hoje são poucos os órgãos existentes, tendo em vista a gravidade da violência e a dimensão do país ${ }^{4}$. Ressalta-se que, somente a partir da Conferência Mundial sobre a Mulher, Estados nacionais passaram a criar órgãos de políticas públicas especificas para as mulheres (LEANDRO, 2014).

No bojo do processo de democratização da sociedade brasileira, de conquistas obtidas com a Constituição e da ratificação, pelo Estado Brasileiro, de tratados internacionais, alguns estados e municípios com articulação feminista previram, em leis orgânicas, a

Pública e 9 núcleos especializados do Ministério Público. Disponível em: $<$ http://agenciapatriciagalvao.org.br/violencia/dad os-e-pesquisas-violencia/dados-e-fatos-sobreviolencia-contra-as-mulheres/>. 
criação de órgãos específicos de proteção às mulheres vítimas de violência, especialmente na modalidade doméstica (BARSTED, 2006; HERMANN, 2006).

Em meados dos anos 80 e início da década de 90 do século passado, foram criados, em algumas regiões do país,órgãos específicos de atendimento, como as Delegacias Especiais em Atendimento às Mulheres (DEAMs), as Casas-Abrigo e os Centros de Referência da Mulher.

As Delegacias Especiais de Atendimento à Mulher (DEAMs) configuraram-se como o primeiro órgão estatal de atendimento às mulheres. A primeira foi criada em agosto de 1985, na cidade de São Paulo, "sob pressão do movimento de mulheres e do Conselho Estadual da Condição Feminina"(SAFFIOTI, 1997, p, 12).

Saffioti (1997) enuncia que as DEAMs foram criadas para prestar serviços especializados diante das necessidades das mulheres em situação de violência doméstica, fazendo-se necessário contar, em seus quadros, com uma estrutura e profissionais multidisciplinares das diversas áreas como: psicólogos/as, assistentes sociais, advogados/as, além de policiais preparados/as e sensíveis à situação das mulheres. No tocante aos Conselhos de Direitos da Mulher, frisa-se que o Conselho Nacional dos Direitos da Mulher (CNDM) surgiu em 1986. Os Conselhos representaram uma das expressões da participação das mulheres na esfera pública (SANTOS, 2006). As Casas Abrigo surgiram nos anos 1990, para mulheres que correm risco de morte em decorrência da violência doméstica. Seu objetivo é proporcionar, por um determinado período, segurança à mulher e os/as filhos/as.

Em 2003, foi criada a Secretaria Nacional de Política para as Mulheres (SPM), com vistas a promover a igualdade entre homens e mulheres e combater todas as formas de preconceito e discriminação herdadas de uma sociedade patriarcal e excludente. (BRASIL, $2011)^{5}$. Em 2005, foi implementado o Plano Nacional de Políticas para as Mulheres (PNPM), o qual pautava, entre as suas

\footnotetext{
${ }^{5}$ Em outubro de 2015 houve a junção da Secretaria de Políticas para as Mulheres com a Secretaria de Promoção da Igualdade Racial e Secretaria de Direitos Humanos.
}

demandas, medidas mais eficazes para a punição dos autores de violência doméstica contra as mulheres. No ano seguinte, uma das mais significativas conquistas dos movimentos feministas foi a sanção da Lei 11340/2006, mais conhecida nacional e internacionalmente como Lei Maria da Penha. Em 2015, foi sancionada a Lei 13.104 que altera o código penal para prever o feminicídio como um tipo de homicídio qualificado e inclui-lo no rol dos crimes hediondos (Decreto-Lei 2.848/1940) ${ }^{6}$.

Conforme o entendimento de Bandeira (2013), feminicídio é o assassinato de uma mulher pela condição de ser mulher. Os crimes geralmente ocorrem na intimidade dos relacionamentos. Suas motivações mais recorrentes são o ódio, o sentimento de perda do controle e da propriedade sobre as mulheres, comuns em sociedades marcadas pela associação de papéis discriminatórios ao feminino, como é o caso brasileiro.

O feminicídio é a instância última de controle da mulher pelo homem: o controle da vida e da morte. Ele se expressa como afirmação irrestrita de posse, igualando a mulher a um objeto, quando cometido por parceiro ou exparceiro; como subjugação da intimidade e da sexualidade da mulher, por meio da violência sexual associada ao assassinato; como destruição da identidade da mulher, pela mutilação ou desfiguração de seu corpo; como aviltamento da dignidade da mulher, submetendo-a a tortura ou a tratamento cruel ou degradante. (BRASIL, 2013, p. 1003).

Para o enfrentamento à violência contra as mulheres, reitera-se a necessidade de articulação entre distintas frentes, a implantação de políticas públicas, o controle social para o efetivo cumprimento das legislações, o desenvolvimento de pesquisas a respeito do tema, a abordagem das relações de gênero nos currículos escolares, a mudança de mentalidades e o fortalecimento das mulheres, como tem sido delineado pelos centros de referência da mulher existentes no país.

\section{A MEDIACÃ O DA INFORMAÇAO NO CENTRO DE REFERENCIA DA}

6 Disponível em:http://www.planalto.gov.br/ccivil_03/_Ato201 5-2018/2015/lei/L13104.htm 


\section{MULHER FÁTIMA LOPES}

A mediação da informação, que permeia todos os processos das relações humanas, é a base fundamental para se adquirir conhecimentos a informação tem um significado singular no que diz respeito ao desenvolvimento da sociedade (SOUZA, 2007).

Na visão de Costa e Almeida Júnior (2012), cabe ao profissional da informação interagir na organização e no tratamento da informação, levando em conta os aspectos culturais, sociais e históricos. É importante salientar a concepção de Almeida Junior (2008, p. 46) a respeito da mediação como "toda interferência - realizada pelo profissional da informação direta ou indireta; consciente ou inconsciente, singular ou plural, individual ou coletiva, que propicia a apropriação da informação que satisfaça, plena ou parcialmente, uma necessidade informacional."

A informação, quando é assimilada de forma adequada, gera a produção do conhecimento e, com isso, traz benefícios ao desenvolvimento do indivíduo e do meio em que ele vive. Segundo Barreto (1994), para que a informação passe a intervir na vida social das pessoas produzindo conhecimento, a mesma precisa ser disseminada e aceita como tal. O autor reflete a respeito da informação como mecanismo simbolicamente significante com a intenção de promover conhecimento no indivíduo, em seu grupo e na sociedade. A informação precisa ser trabalhada na qualidade de mediadora do conhecimento, tendo finalidade de gerar novos conhecimentos, visto que a informação é "[...] capaz de criar ou informar novos contextos de significado." (NASCIMENTO; MARTELETO, 2004, p. 8).

Segundo Araújo (1992) a informação possui um valor social determinante para ampliação dos direitos sociais. Todo ser humano tem direito à informação, pois esta é uma etapa essencial para o aprendizado da cidadania. Ainda seguindo o pensamento da autora, a informação tem uma ação transformadora na vida do indivíduo, na produção de novos conhecimentos, visto que tanto a informação quanto o conhecimento podem transformar relações de poder, as quais subordinam e discriminam mulheres, negros/as, homossexuais, e pessoas com deficiências, entre outros.
Uma informação interpretada de forma correta é capaz de produzir um conhecimento adequado. Isso pressupõe uma comunicação compreensível e consequentemente geradora de novos conhecimentos, que vão realimentar o desenvolvimento de cada indivíduo. O que confirma essa perspectiva é que a falta de informações corretas impede $\mathrm{o}$ acesso das pessoas às realidades que as cercam, isto é, "como e por que as coisas acontecem" (MARTELETO; RIBEIRO, 2001, p. 3).

Conforme aponta Targino (1991, p. 155)

A informação é, portanto, direito de todos. É um bem comum, que pode e deve atuar como fator de integração, democratização, igualdade, cidadania, libertação, dignidade pessoal. Não há exercício de cidadania sem informação. Isto porque, até para cumprir seus deveres e reivindicar seus direitos, sejam eles, civis, políticos ou sociais, o cidadão precisa conhecer e reconhecê-los e isto é informação.

No tocante à violência contra mulheres, a informação ocupa uma posição central, levando acessibilidade para mulheres em situação de violência. Conforme aponta Cortês; Luciano; Dias (2012, p. 135):

A informação ocupa uma posição de centralidade para que as mulheres tenham acesso aos serviços disponíveis na rede de atendimento, conheçam os seus direitos e se fortaleçam para superar o medo, a vergonha, o isolamento e o preconceito, que perpassam a dinâmica da violência.

No que tange a bibliotecários/as, consideramos que a atuação em bibliotecas e demais unidades informacionais, a exemplo do centro de referência da mulher, é essencial para o combate à violência contra mulheres: tanto no processo de tomada de decisões e quanto no planejamento de políticas públicas capazes de combater, prevenir e erradicar a violência. A informação é uma ferramenta essencial para fortalecer o monitoramento e aprimoramento de ações que busquem alterar a desigualdade que afeta a vida de milhares de mulheres cotidianamente.

Como afirma Lauretis (1994, p. 209)"a construção do gênero também se faz por meio de sua desconstrução". Desse modo, é mister a ressignificação de conceitos, símbolos, representações essencialistas e imutáveis 
acerca das desigualdades entre mulheres e homens. Esta discussão acena para a importância da informação como estratégia potencial para a transformação das práticas, discursos, mentalidades e socialização de mulheres e homens. González de Gómez (2012) enuncia que a informação se associa à transmissão cultural e aos processos de socialização e formação de identidades. A informação constitui um bem simbólico e o acesso a ela é fundamental para ampliação dos direitos sociais de mulheres e homens (MORIGI; VANZ; GALDINO, 2002). A prática da/o bibliotecária/o está relacionada com o interesse pela sociedade e suas necessidades informacionais. Desta forma o/a bibliotecário/a, na qualidade de profissional da informação, assume um papel importante no processo de mediação da informação. $\mathrm{O}$ tratamento, a organização e a difusão da informação referente aos órgãos de atendimento e de estatísticas oficiais sobre o perfil das mulheres, a exemplo do presente estudo, podem influenciar na formação e transformação de mentalidades a respeito dos direitos das mulheres.

\subsection{CAMPO DA PESQUISA - CENTRO ES- TADUAL DE REFERÊNCIA DA MULHER FÁTIMA LOPES}

Os equipamentos públicos específicos para o acolhimento/atendimento psicológico, social, orientação jurídica à mulher em situação de violência, os centros de referência da mulher, começaram a ser criados somente na década de $1990^{7}$. Segundo a Norma Técnica de Uniformização dos Centros de Referência da Mulher, os centros são:

[...] espaços de acolhimento/atendimento psicológico, social, orientação e

\footnotetext{
${ }^{7} \mathrm{O}$ primeiro órgão público municipal implantado no país com estas características foi a Casa Eliane de Grammont, criada em 09 de março de 1990. A Casa teve importante papel na construção de uma metodologia de atenção, tornando-se modelo para as poucas experiências semelhantes. Em agosto de 1996, foi criado pela prefeitura de Belo Horizonte, o Benvinda. Em Porto Alegre, o Centro de Referência da Mulher "Vânia Araújo Machado", foi criado em 2002. (SILVEIRA, 2006).
}

${ }^{8}$ A Rede de Atendimento reúne ações e serviços das
áreas da assistência social, justiça, segurança
pública e saúde, integrando a Rede de encaminhamento à mulher em situação de violência, que proporcione $\mathrm{o}$ atendimento e $\mathrm{o}$ acolhimento necessários à superação da situação de violência ocorrida, contribuindo para o fortalecimento da mulher e o resgate da sua cidadania. (BRASIL, 2006, p. 15).

A equipe delineia ações de aconselhamento em momentos de crise; atendimento psicossocial, aconselhamento e acompanhamento jurídico, atividades de prevenção, qualificação de profissionais e articulação da rede de atendimento $\operatorname{local}^{8}$. Além disso, os centros têm, entre seus objetivos, a discussão da construção social de gênero e o resgate da cidadania, autoestima e confiança nas próprias percepções e decisões das mulheres (SILVEIRA, 2006).

O Estado da Paraíba conta com equipamentos importantes para $\mathrm{O}$ enfrentamento à violência contra as mulheres, quais sejam: Orgãos de Políticas para as Mulheres (49), Centros de Referência da Mulher (14) (Campina Grande, Cajazeiras, João Pessoa, Patos e Santa Luzia.), Casa Abrigo Aryane Thais, catorze Delegacias Especializadas de Atendimento à Mulher (João Pessoa (2), Cabedelo (1), Bayeux (1), Campina Grande (1), Guarabira (1), Patos (1), Cajazeiras (1), Sousa (1), Monteiro (1), Mamanguape (1), Picuí (1)), Queimadas (1), Santa Rita (1) um núcleo de delegacia na Seccional de Esperança e Hospitais de Referência no atendimento às mulheres em situação de violência doméstica e sexual, entre outros equipamentos. Atualmente, no Brasil, existem 235 centros de referência da mulher em diferentes regiões do país. Destes, catorze estão localizados no estado da Paraíba.

Enfrentamento, ao englobar o eixo de assistência previsto na Política Nacional de Enfrentamento à Violência Contra as Mulheres. Entre as instituições e serviços estão: Delegacias Especializadas de Atendimento à Mulher, Centros de Referência de Atendimento à Mulher, Juizados de Violência Doméstica e Familiar contra a Mulher, Órgãos da Defensoria Pública, Serviços de Saúde Especializados para o Atendimento dos Casos de Violência Contra a Mulher. Disponível em; http://www.compromissoeatitude.org.br/rede-deatendimento-as-mulheres-em-situacao-deviolencia/ 


\begin{tabular}{|l|l|}
\hline Quadro 2 - Centros de Referência da Mulher na Paraíba & CIDADE \\
\hline CENTROS DE REFERÊNCIA DA MULHER & Cajazeiras \\
\hline Centro de Referência de Atendimento à Mulher (Cram) Suzane Alves da Silva & João Pessoa \\
\hline Centro de Referência da Mulher (CRM) Ednalva Bezerra & Santa Luzia \\
\hline Centro de Referência de Atenção à Mulher (Cram) & Campina Grande \\
\hline Centro Estadual de Referência da Mulher Fátima Lopes & Campina Grande \\
\hline Centro de Referência Municipal da Mulher de Campina Grande & Patos \\
\hline Centro de Referência da Mulher de Patos & \\
\hline
\end{tabular}

Fonte: Dados da Pesquisa, 2017.

O Centro Estadual de Referência da Mulher Fátima Lopes (CRMEFL), Figura 1, campo da pesquisa, foi implantado no dia 12 de dezembro de 2012. Está ligado à Secretaria Estadual de Políticas Públicas para as Mulheres (SPPM) do Estado da Paraíba ${ }^{9}$. A equipe multiprofissional realiza acolhimento com atenção especial às mulheres em situação de violência, oferecendo atendimento social, psicológico, jurídico e arte-educação com as mulheres em situação de violência doméstica e familiar. ${ }^{10}$

Figura1-Centro Estadual de Referência da Mulher Fátima Lopes Figura 2- Campanha do CRMFL

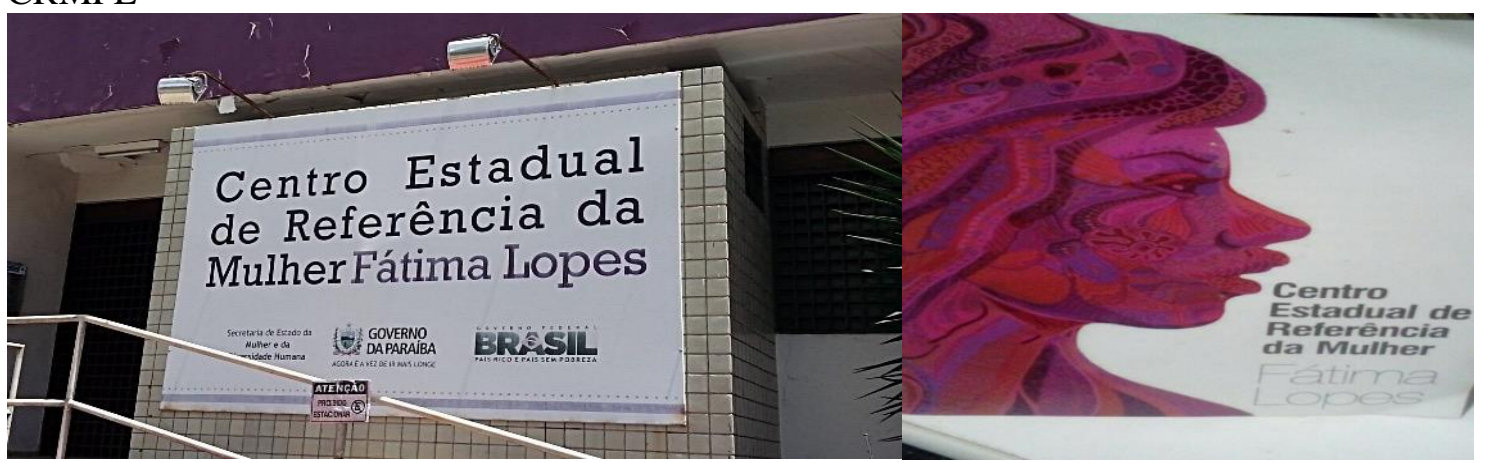

Fonte: Acervo fotográfico do CERMFL

Fonte: Acervo fotográfico do CERMFL

A mulher que procura o equipamento é acolhida pelas profissionais que, depois de escutá-la, encaminham-na para o atendimento necessário no próprio CERMFL ou para serviços externos da rede de atendimento - serviços de assistência social, de justiça, segurança e saúde, entre outros. O CERMFL realiza ações de intervenção na comunidade, por meio da realização de palestras e oficinas para formação em relações de gênero, Lei Maria da

\footnotetext{
${ }^{9}$ A Secretaria Extraordinária de Políticas Públicas para Mulheres tem como papel fundamental contribuir para a promoção da equidade de gênero, por meio da implementação de políticas públicas que efetivem os direitos humanos das mulheres e elevem sua cidadania, superando as situações de desigualdades vivenciadas pela mulher na sociedade. A secretaria estadual está ligada à secretaria nacional. Disponível em: http://www.spm.gov.br/assuntos/organismos-
}

governamentais-df-estados-emunicipios/dados/estados/paraiba.

${ }^{10} \mathrm{O}$ órgão presta uma homenagem à defensora pública Fátima Lopes, morta em acidente automobilístico no ano de 2010, em João Pessoa. O equipamento funciona de segunda a sexta-feira, das $8 \mathrm{~h} 00$ às $18 \mathrm{~h} 00$, e atende às mulheres de Campina Grande e das cidades vizinhas. Informações obtidas com a coordenadora do CERMFL. 
Penha, em escolas, centros de saúde, universidades, dentre outros. O centro possui também atendimento via telefone (180), para direcionar as mulheres aos serviços existentes no Estado e Município.

\section{METODOLOGIA}

Esta pesquisa surgiu a partir da interação pesquisador/a e comunidade pesquisada promovendo ações de construção, troca e disseminação da informação. Utilizamos, inicialmente, a pesquisa exploratória e bibliográfica. O estudo alicerçou-se, também, na pesquisa descritiva, buscando descrever as carcaterísticas, as experiências, as relações existentes nas comunidades, grupos ou realidade a ser pesquisada (CERVO; BERVIAN;SILVA, 2007). Para alcançar as finalidades da pesquisa, usamos a abordagem quantitativa. Com a pesquisa quantitativa, objetivamos conhecer melhor indicadores e tendências observáveis do perfil das mulheres atendidas no CERMFL (MINAYO; SANCHES, 1993). Foram realizadas reuniões com professores/as, alunas e a equipe do CERMFL, com objetivo de conhecer a dinâmica do CERMFL, interagir com a equipe multiprofissional, identificar as necessidades informacionais e o fluxograma de atendimento.

Posteriormente, por meio da pesquisa documental, a coleta foi centrada nas fichas de atendimento das 78 mulheres recebidas em 2015. Organizamos os dados, criamos categorias classificatórias e os registros foram transferidos e sistematizados no software Excel. A análise dos dados foi dinamizada através da estatística descritiva.

O CERMFL configura-se como uma unidade informacional que tem como usuárias as mulheres que estão em situação de violência e busca oferecer, por meio dos seus serviços, meios que possam contribuir para que a mulher rompa com a situação de violência. Para oferecer um serviço de qualidade, é essencial realizar estudos e pesquisas para conhecer as usuárias e suas necessidades informacionais. Conhecer o perfil das usuárias visa contribuir para o planejamento dos serviços de informação, criação de sistemas de informação, bem como organização, armazenamento, disseminação e recuperação das informações.

\section{RESULTADOS E DISCUSSÕES: BREVE PERFIL DAS MULHERES ATENDIDAS NO CENTRO DE REFERÊNCIA FÁTIMA LOPES}

Nosso objeto de estudo é a unidade informacional Centro de Referência da Mulher Fátima Lopes. As informações estatísticas inseridas nos gráficos abaixo decorrem da pesquisa realizada com usuárias do CERMFL no ano de 2015. O perfil das mulheres será apresentado a partir da categorização por faixa etária, tipo de violência sofrida, local de ocorrência da violência, dentre outras, almejando potencializar as ações desenvolvidas pelo órgão.
Gráfico1 - Cidade

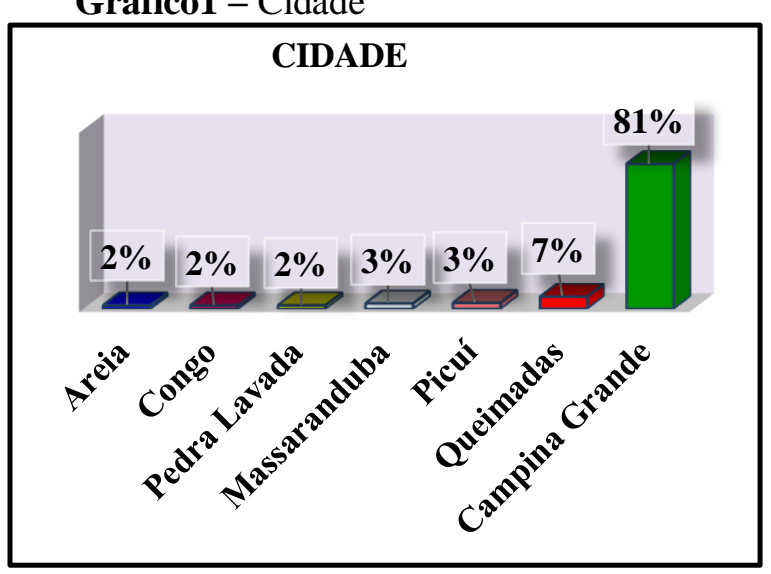

Fonte: Dados da Pesquisa, 2017.
Gráfico 2 - Faixa Etária

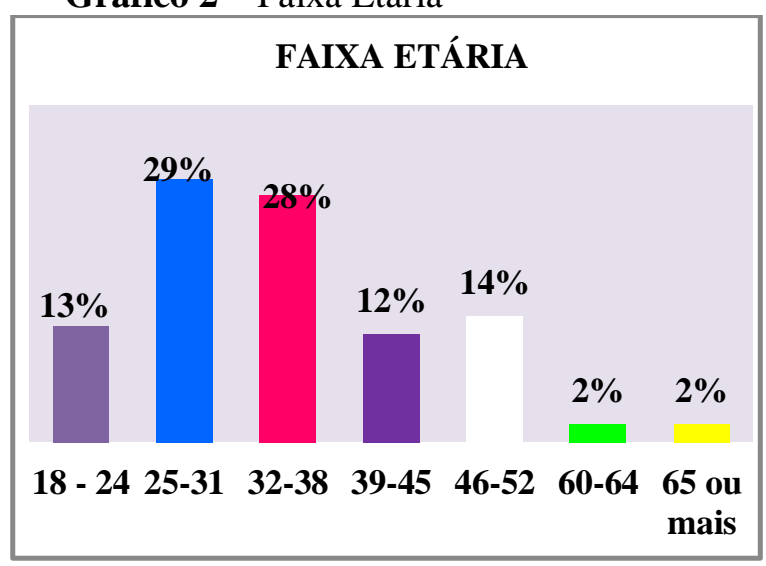

Fonte: Dados da Pesquisa, 2017.
O CERMFL é um equipamento estadual e atende mulheres de diferentes municípios do
Estado. O gráfico 1 aponta que a cidade em que as mulheres mais têm acessado o CREMFL, é 
Campina Grande com (81\%). Queimadas (7\%), Massaranduba e Picuí respectivamente com (3\%) e Pedra Lavrada, Congo e Areia com (2\%) em seguida. Ressalta-se que em Queimadas ocorreu o bárbaro estupro coletivo $^{11}$.

Em relação à faixa etária, de acordo com as informações do gráfico 2 , as usuárias que buscaram o CERMFL, em 2015, são em sua maioria mulheres jovens, (42) das mulheres estão na faixa etária entre 18 a 31 anos, (28) entre 32 a 38 anos, (26 concentravam-se na faixa de 39 - 52 anos e (4\%) 60 ou mais. Destaca-se que mais metade, $57 \%$ estão na faixa entre 25 a 38 anos. Segundo o Mapa da Violência 2013: Homicídios e Juventude no
Brasil, as mulheres mais jovens no Brasil estão mais suscetíveis a sofrer violência. Em 2011, a taxa de homicídios entre mulheres com idades entre 15 e 24 anos foi de 7,1 mortes para cada 100 mil, enquanto a média para as não jovens foi de 4,1 (WAISELFISZ, 2013). O fato das mulheres acima de 60 anos não estarem entre o grupo com maior incidência de violência não implica dizer que elas não tenham sofrido violência. Pesquisas qualitativas são necessárias para aprofundar a questão, mas pode-se inferir que as mulheres desta faixa de idade podem não acessar o órgão em decorrência da incorporação de padrões dominantes de gênero, sendo mais difícil publicizar a violência.

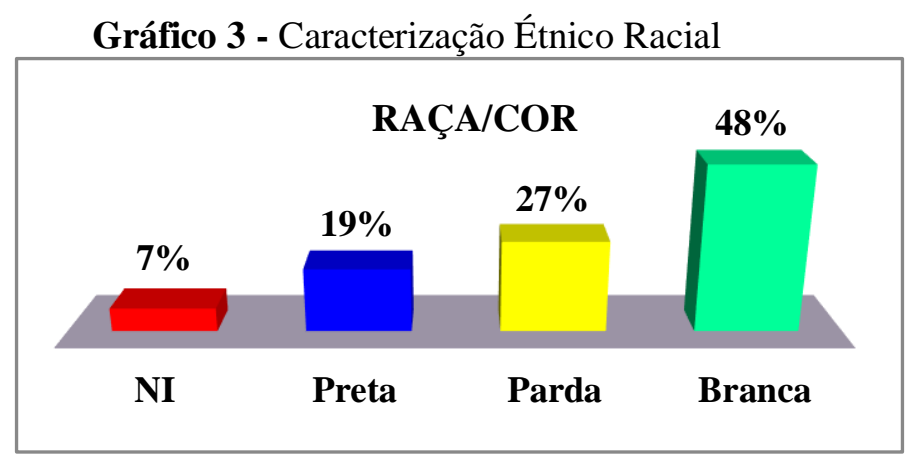

Fonte: Dados da Pesquisa, 2017

No que se refere ao quesito raça/cor, gráfico 3 a classificação foi realizada de acordo com o Instituto Brasileiro de Geografia e Estatística (IBGE) ${ }^{12}$ após a mediação da informação da equipe da pesquisa. No período anterior à pesquisa, os dados referentes à caracterização étnico racial não eram padronizados. Ao observar a caracterização étnico racial, gráfico 3, verifica-se que dentre as mulheres em situação de violência (19\%) se declaram preta, (27\%) parda, e (48\%) brancas. E um índice de $(7 \%)$ de mulheres, não informaram ${ }^{13}$ a sua caracterização étnicoracial, ou não teve o registro computado na

${ }^{11}$ No dia 12 de fevereiro de 2012, ocorreu em Queimadas a trágica notícia de estupro coletivo de cinco mulheres. $\mathrm{O}$ estupro ocorreu como presente de aniversário de um irmão para o outro, com a participação de dez homens, entre esses, 3 adolescentes. Os suspeitos foram presos em 24 horas. ficha de atendimento. Se somarmos pardas e pretas, as mulheres não brancas chegam a (46\%). Não foi localizado, na pesquisa, mulheres que se autodeclaram indígenas e amarelas.

Dados apresentados pelo Mapa da Violência 2015 revelam que, na década 20032013, houve um aumento de 54,2\% no total de assassinatos de mulheres negras, aumentando de 1.864, em 2003, para 2.875, em 2013.

A vitimização de mulheres negras - a violência contra elas, que pode não ter se concretizado como homicídio - cresceu 190,9\% na década analisada. A vitimização

12 Utilizamos a categorização do IBGE para classificar os dados: Branca, Preta, Parda, Amarela e Indígena.

${ }^{13}$ NI- Não Informado. 
desse grupo era de $22,9 \%$, em 2003 , e saltou $66,7 \%$ no ano passado. Alguns estados chegam a limites absurdos de vitimização de mulheres negras, como Amapá, Paraíba, Pernambuco e Distrito Federal, em que os índices passam de $300 \%$ [...]. (NEGRAS..., 2015). ${ }^{14}$

As relações entre gênero e raça formam um emaranhado de complexidades, pois a interseção de gênero com raça dificulta o acesso das mulheres nas mais distintas esferas sociais.

Em relação à expectativa de vida e saúde, a situação das mulheres negras no Brasil diverge com a tendência mundial de que as mulheres vivem mais que os homens. A expectativa de vida para mulheres negras é de 66 anos. No que diz respeito à saúde, a precária situação da saúde sexual e reprodutiva das mulheres negras está continuamente relacionada à desigualdade de acesso aos serviços de saúde. Frisa-se que os dados são subnotificados, em vista de não existir dados nacionais consolidados sobre o quesito raça/cor nos formulários de educação, saúde, habitação, dentre outros, nos organismos públicos (WERNECK; NILZA, 2016).

Carneiro (2003) enuncia que as condições históricas das mulheres negras foram construídas sobre uma relação de coisificação,

Gráfico 4 - Renda

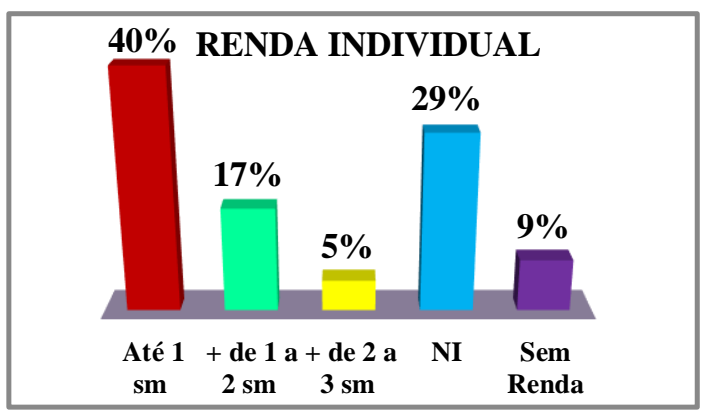

Fonte: Dados da Pesquisa, 2017.

Analisando o gráfico 4 em relação à renda, no ano de 2015, podemos observar que $40 \%$ das mulheres em situação de violência vive em condições precárias ganhando somente até um em que a dominação e a apropriação sexual das mulheres resultavam na afirmação de superioridade dos homens brancos. A violência é potencializada nas mulheres negras por serem mulheres e por serem negras e se agrava quando são pobres. Os reflexos do racismo são vivenciados cotidianamente pelas mulheres negras que encontram maiores dificuldades para se inserirem em diferentes setores da sociedade.

No que concerne aos índices de violência sofrida por mulheres negras, Werneck e Nilza (2016), afirmam que, apesar do Brasil ser signatário de Tratados Internacionais, possuir legislação especifica como a Lei Maria da Penha, e redes de serviços, não existem instrumentos específicos para o enfrentamento do racismo e seus impactos na produção da violência contra as mulheres negras. Em geral, a violência doméstica e familiar cometida contra as mulheres negras não é registrada em termos de tematizações raciais, sendo o quesito raça inexistente ou sem preenchimento nas fichas de identificação de órgãos públicos e privados. Evidencia-se, assim, a necessidade de estudos acadêmicos sobre o assunto e ações do poder público que contemplem a intersecção classe, raça e gênero para o enfrentamento da violência contra as mulheres.

Gráfico 5 - Ocupação

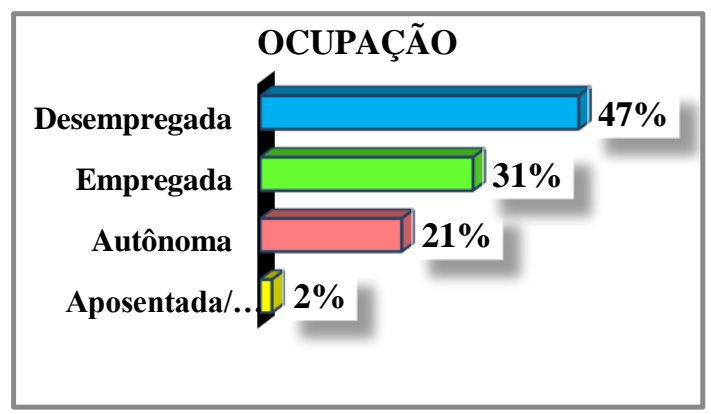

Fonte: Dados da Pesquisa, 2017.

salário mínimo, $17 \%$ de um a dois salários mínimos, 29\% não informaram, 5\% afirmaram ganhar de dois a três salários mínimos, e $9 \%$ disseram não ter renda alguma. Ou seja, mais

${ }^{14}$ Disponível em http://www.brasil.gov.br/defesae-seguranca/2015/11/mulheres-negras-sao-maisassassinadas-com-violencia-no-brasil/\#acontent. Acesso em: Acesso em: 12 nov. 2017). 
da metade das mulheres atendidas (57\%) ganham até dois salários. Percebe-se aqui uma lacuna na ficha de atendimento por parte das usuárias, com um índice muito alto de mulheres que não informaram a renda. Quando observamos a variável da situação no mercado de trabalho Gráfico 5, 2\% das mulheres são aposentadas ou estão em situação de auxílio doença, $21 \%$ se declaram autônomas ou inseridas em trabalho informal, $31 \%$ estão com vínculos empregatícios no mercado de trabalho e quase metade das mulheres $47 \%$ encontram-se desempregadas, o que aponta a ausência de autonomia financeira e a situação de exclusão social.

Apesar da crescente participação feminina em diversos setores da sociedade, e maior acesso à escolarização, há grandes desafios para a participação mais justa e igualitária de todas as mulheres no mercado de trabalho. Houve um leve aumento do rendimento feminino entre

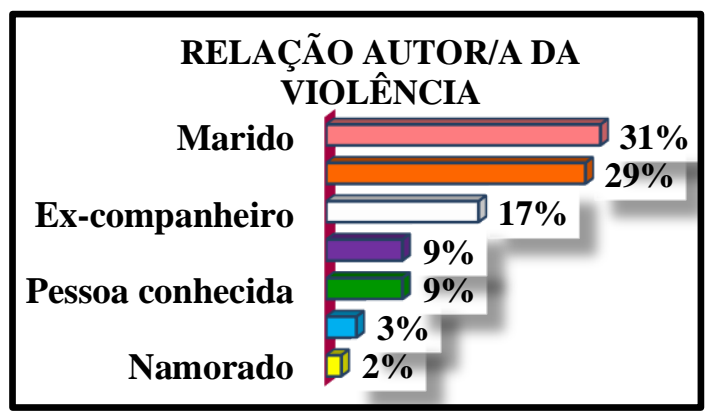

Gráfico 6 - Relação autor/a da violência

Gráfico 7 - Local da ocorrência

Fonte: Dados da Pesquisa, 2017

Quanto à situação conjugal das mulheres pesquisadas, verificamos que $2 \%$ são viúvas, $3 \%$ separadas, desquitadas, ou divorciadas, $33 \%$ solteiras, e $62 \%$ estão casadas ou em união estáve $\mathrm{l}^{16}$. Podemos observar ainda que,

\footnotetext{
${ }^{15}$ Disponível

em: $<$ http://www.diariodaamazonia.com.br/estudoaponta-melhoria-na-renda-das-mulheres-brasil >. Acesso em: 13 nov. 2017.
}

2000 e 2010, mas as mulheres ainda recebem, em média, $74,5 \%$ do rendimento dos homens, de acordo com a Pesquisa Nacional por Amostra de Domicílios (Pnad) 2014. É importante ressaltar que a precarização do trabalho, o desemprego, a exploração do/a trabalhador/a, decorrentes do sistema capitalista, atinge mulheres e homens, influenciando nas condições objetivas de ambos, mas as consequências da exploração do trabalho se potencializam na articulação entre classe, gênero e raça. Outro fato evidenciado na pesquisa do PNAD refere-se à influência da regionalidade. "A média do rendimento de uma trabalhadora do Centro-Oeste era $80,5 \%$ maior do que o de uma nordestina" (ESTUDOS..., 2015). ${ }^{15}$

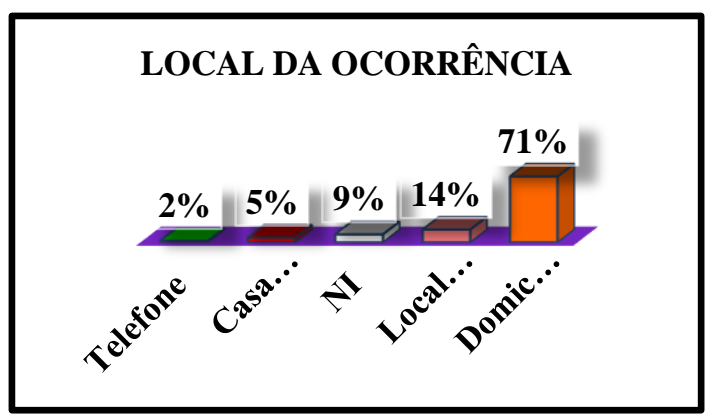

Fonte: Dados da Pesquisa, 2017.

entre essas mulheres, o maior índice de violência é aquela cometida por parceiro íntimo. O Gráfico 6 evidencia que, somando os dados do companheiro, marido, namorados e ex, eles são a maioria absoluta dos agressores

16 Sep./Div./Desq. (Separada, Divorciada ou Desquitada). 
(60\%). Parentes correspondem a 9\%, assim como pessoas conhecidas. $3 \%$ das mulheres não informaram sua relação com o agressor. Identificamos que nenhuma das mulheres da pesquisa sofreu algum tipo de violência por pessoa desconhecida.
A pesquisa expõe, ainda, que o local onde mais ocorreu violência foi o domicílio, com o percentual de $71 \%$. Ou seja, a casa, que deveria representar um local agradável e seguro para essas mulheres, vem a ser um lugar de risco, onde as mulheres têm vivenciado as situações de violência.

Gráfico 8 - Tipo de violência

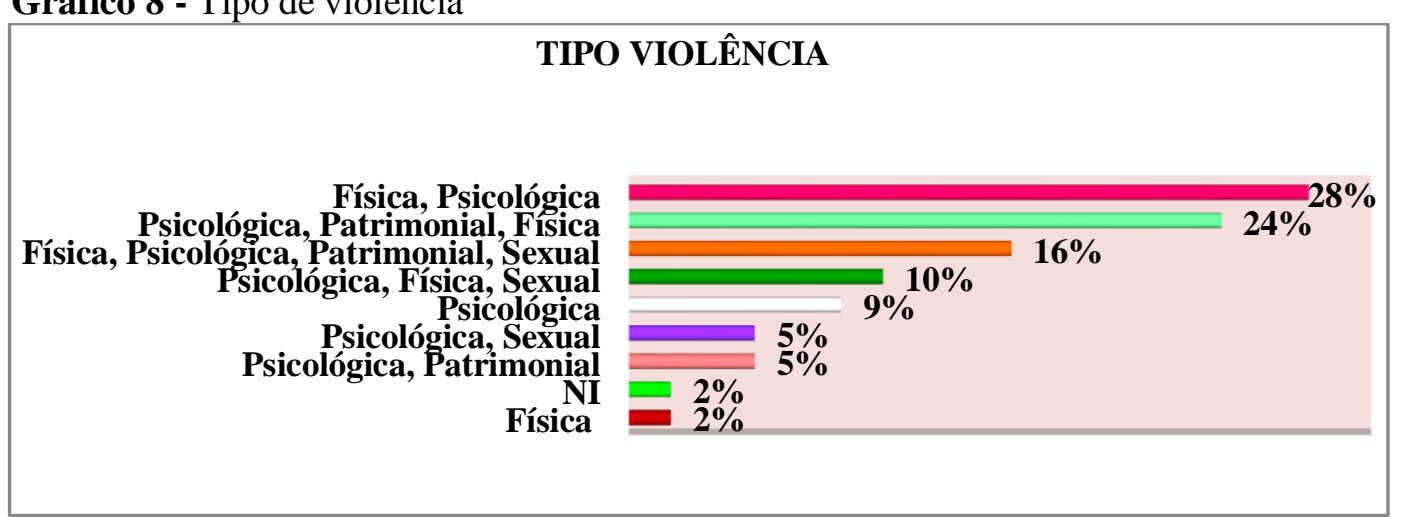

Fonte: Dados da Pesquisa, 2017

Como podemos verificar no Gráfico 8, isoladamente, apenas $2 \%$ das mulheres afirmam ter sofrido violência física. Quando observamos a violência física acompanhada das demais, explicita-se que $80 \%$ das mulheres que procuraram o centro sofreram este tipo de violência. Em relação à violência psicológica,9\% disse tê-la sofrido isoladamente. Quando somada a violência psicológica às demais, percebemos que $97 \%$ delas sofreram violência psicológica. Em geral, a violência psicológica é o pano de fundo para a ocorrência de outros tipos de violência, e muitas vezes ela é naturalizada, passa despercebida, vem disfarçada pelo ciúme, humilhações, ameaças, rejeições, controles e insultos (SILVA; COELHO; CAPONI, 2007). Analisando o gráfico não verificamos a violência sexual isoladamente, mas em conjunto com outras violências $(31 \%)$. A violência patrimonial também foi identificada, chegando a $45 \%$ dos casos. Outras observações são que $16 \%$ das mulheres sofreram os quatro tipos de violência e $2 \%$ não informaram o/os tipo/s de violência sofrida.

As informações produzidas, respeitando os limites do estudo, contribuem para o conhecimento do perfil das mulheres atendidas no CERMFL, para o dimensionamento da realidade local, e, consequentemente fornece subsídios para o monitoramento da problemática e para a realização de novas propostas de programas e pesquisas a respeito do tema.

\section{CONSIDERAÇÕES FINAIS}

A informação é essencial para a tomada de decisões mais precisas e para o planejamento de políticas públicas que visem potencializar as resistências das mulheres frente às mais distintas desigualdades. Corroborando a concepção de que a informação se configura como fonte de saber e poder, a organização, produção e disseminação de informações estatísticas são instrumentos indispensáveis para o empoderamento das mulheres e a subversão da situação de violência.

Respeitando os limites do estudo, as informações produzidas contribuem para o conhecimento do perfil das mulheres atendidas no CERMFL, para o dimensionamento da realidade local, e, consequentemente fornece subsídios para o monitoramento da problemática e para a realização de novas pesquisas a respeito do tema. Verificou-se a situação de vulnerabilidade social das mulheres que acessaram o CERMFL, assim como se revelou que a combinação das assimetrias de gênero, classe e raça potencializa a situação de desigualdade. 
A realização da pesquisa, articulando a violência contra as mulheres e a biblioteconomia, configurou-se como um desafio, tendo em vista a carência de estudos com esta interface. Explicitou-se que a atuação do/a bibliotecário/a na organização, disseminação e compartilhamento de informação a respeito da violência contra as mulheres é fundamental, assim como sua atuação em unidades informacionais não tradicionais, a exemplo do CERMFL. O trabalho do/a bibliotecário/a nesta seara pode ser dinamizado em bibliotecas e demais unidades informacionais, por meio de divulgação do acervo referente às relações de gênero e à violência contra as mulheres, por rodas de conversa, exposição de livros e fotografias, como também pela realização de pesquisas que abordem o tema.
As informações produzidas mostraram a complexidade da violência contra as mulheres e o seu caráter multidimensional. O desenvolvimento de ações intersetoriais para a prevenção e o enfrentamento da violência, como a articulação da rede de enfrentamento à violência, dos setores de saúde, educação, cultura e segurança são essenciais para a coibição da violência. É essencial frisar, neste contexto, a importância da atuação das universidades neste combate, por meio de projetos de pesquisa, extensão e da inclusão da temática nos currículos de graduação.

Espera-se que as informações estatísticas produzidas gerem novos conhecimentos, estimulem pesquisas e forneçam subsídios para estabelecer o monitoramento e a construção de políticas públicas efetivas para garantir às mulheres o direito à vida.

\title{
VIOLENCE AGAINST WOMEN AND THE MEDIATION OF THE LIBRARIAN - A PROFILE OF THE WOMEN LOOKED AFTER AT THE REFERENCE CENTER FOR WOMEN FÁTIMA LOPES
}

\section{Abstract}

\begin{abstract}
Domestic violence is constituted as a social problem and a violation of human rights that affects women in their daily lives. The absence of official information about the dynamics of violence and the profile of the women received by support organs represent a challenge in the planning of public policies adapted to the needs of women. Considering that access to information can contribute to the reduction of violence and the production of new knowledge, this proposal aims to present the State Reference Center for Women Fátima Lopes/Campina Grande (CERMFL), a public agency for specific attention to the women in situation of violence. The work delineates the profile of these women, focusing on age group, ethnic characterization, marital situation, income, town, relation with the author of the violence, occurrence place and type of suffered violence. It is a descriptive research with quantitative approach, which used documentary sources, specifically the registers of 2015 's cases. Descriptive statistic was used in data analysis. By means of the statistic information produced in this study, it is verified that violence against women demands intersectoral action for the strengthening of women and the rupture of the situation of violence. It is noted that the treatment, production and dissemination of official statistic information are indispensable for the improvement of public policies directed to prevention and eradication of violence and the violation ofhuman rights.
\end{abstract}

Keywords: Domestic violence. Information. Reference Center for Women. Mediation of Information. Gender relations.

\section{REFERÊNCIAS}

ALMEIDA JÚNIOR, O. F. Mediação da informação: ampliando o conceito de disseminação. In: VALENTIM, M. L. P. (Org.). Gestão da informação $\mathrm{e}$ do conhecimento no âmbito da Ciência da
Informação. São Paulo: Cultura Acadêmica, 2008. p. 41-54.

ARAÚJO, Eliany Alvarenga de. Informação, cidadania e sociedade no Brasil. Informação \& Sociedade: Estudos, João Pessoa, v. 2, n. 1, p. 42-49, jan./dez. 1992. 
BARRETO, Aldo de Albuquerque. A questão da informação. Revista São Paulo em Perspectiva, São Paulo, v.8, n.4, 1994.

BARSTED, L. L. O avanço legislativo no enfrentamento da violência contra as mulheres. In: LEOCADIO, E.; LIBARDONI, M. (Orgs.). O desafio de construir redes de atenção ás mulheres em situação de violência. Brasília: AGENDE, 2006. p. 65-90.

BRASIL. Lei $n^{\circ}$. 11.340, de 7 de agosto de 2006. Disponível em:<https://presrepublica.jusbrasil.com.br/leg islacao/95552/lei-maria-da-penha-lei-1134006>. Acesso em: 13 nov. 2017.

BRASIL. Presidência da República. Secretaria Especial de Políticas para as Mulheres. Rede de Enfrentamento à Violência contra as Mulheres. Brasília, 2011.

BRASIL. Senado Federal. Comissão Parlamentar Mista de Inquérito. Relatório Final. Brasília, 2013.

CAMPOS, M. L.; ALMEIDA, G. H. M. D. Violence against women: a relation between subjective dimension sand the production of information. Revista Digital de Biblioteconomia \& Ciência da Informação, v. 15, n. 2, 2017. Disponível em: <http://www.brapci.inf.br/v/a/27487>. Acesso em: 12 nov. 2017.

CARNEIRO, Sueli. Mulheres em movimento. Estudos Avançados, São Paulo, v. 17, n. 49, 2003.

CERVO, Amado Luiz; BERVIAN, Pedro Alcino; SILVA, Roberto da. Metodologia científica. São Paulo: Pearson Prentice Hall, 2007.

CÔRTES, G. R.; LUCIANO, M. C. F.; DIAS, K. C. O. A informação no enfrentamento à violência contra mulheres: Centro de Referência da Mulher "Ednalva Bezerra": relato de experiência. Biblionline, João Pessoa, v.8, p.134-151, 2012. Edição especial.

COSTA, M. F. O.; Almeida Júnior, O. F. Os conceitos de estudos de usuários e a visão do bibliotecário no processo de mediação da informação. In: CAVALCANTE, L. E.; PINTO, V. B.; VIDOTTI, A. B. G. (Orgs.).
Ciência da Informação e

Contemporaneidade: tessituras e olhares. Fortaleza: Edições UFC, 2012.

CRIPPA, G. O pensamento da diferença e a mediação da informação institucional em bibliotecas públicas: considerações teóricas sobre mediação de gênero. Tendências da Pesquisa Brasileira em Ciência da Informação, Belo Horizonte, v. 4, n 1, 2011. Disponível em: <http://inseer.ibict.br/ancib/index.php/tpbci/art icle/viewfile/46/83>. Acesso em: 13 nov. 2017.

ESTUDOS apontam melhoria na renda das mulheres no Brasil. Diário da Amazônia, 26 abr. $2015 . \quad$ Disponível em: $<$ http://www.diariodaamazonia.com.br/est udo-aponta-melhoria-na-renda-das-mulheresbrasil>. Acesso em: 13 nov. 2017.

GONZÁLEZ DE GÓMEZ, Maria Nelida. As Ciências Sociais e as Questões da Informação. Morpheus: Revista Eletrônica em Ciências Humanas, Rio de Janeiro, ano 9, n. 14, 2012.

HERMANN, J. A violência contra a mulher em números; dificuldades e desafios. In: LEOCADIO, E.; LIBARDONI, M. (Orgs.). O desafio de construir redes de atenção ás mulheres em situação de violência. Brasília: AGENDE, 2006. p. 91 - 112.

LAURETIS, T. A tecnologia do gênero. In: HOLLANDA, B.H. Tendências e impasses: $o$ feminismo como crítica da cultura. Rio de Janeiro: Rocco, 1994.

LEANDRO, A. U. F. Implementação de políticas públicas e desafios ao enfrentamento da violência contra a mulher. In: SEMANA DE PÓS GRADUAÇÃO EM CIÊNCIA POLÍTICA: REPENSANDO A TRAJETÓRIA DO ESTADO BRASILEIRO, 2., 2014, São Carlos. Anais... São Carlos, SP: UFSCar, $2014 . \quad$ Disponível em: <http://www.semacip.ufscar.br/wpcontent/uploads/2014/12/Implementa\%C3\%A 7\%C3\%A3o-de-pol\%C3\%ADticasp\%C3\%BAblicas-e-desafios-aoenfrentamento-da-viol\%C3\% AAncia-contraa-mulher.pdf >. Acesso em: 13 nov. 2017.

LOURO, Guacira Lopes. Nas redes do conceito de gênero. In: LOPES, M. J. D.; MEYER, D. E.; WALDOW, V. R, (Orgs.). 
Gênero e saúde. Porto Alegre, RS: Artes Médicas, 1996.

LOURO, Guacira Lopes. Gênero, sexualidade e educação: uma perspectiva pós-estruturalista. 6. ed. Rio de Janeiro: Vozes, 1997.

MARTELETO, Regina Maria; RIBEIRO, Leila Beatriz. Informação e construção do conhecimento para a cidadania no terceiro setor. Informação \& Sociedade: Estudos, João Pessoa, v. 11, n. 1, 2001.

MATOS, M. Feminismo. In: Dicionário Feminino da Infâmia: Acolhimento e Diagnóstico de Mulheres em Situacão de Violência. FLEURY-TEIXEIRA, E.; MENEGHEL, S. (Orgs.) Dicionario Feminino da Infâmia. Rio de Janeiro: FIOCRUZ, 2015.

MINAYO, M. C.; SANCHES, O. Quantitativo-qualitativo: oposição ou complementariedade? Caderno de Saúde Pública, São Paulo, v. 9, n. 3, p. 239-262, 1993.

MORIGI, Valdir José; VANZ, Samile Andréa de Souza; GALDINO, Karina. O bibliotecário e suas práticas na construção da cidadania. Revista ACB: Biblioteconomia em Santa Catarina, Santa Catarina, v. 7, n. 1, 2002.

NASCIMENTO, D. M; MARTELETO, R. M. A informação construída nos meandros dos conceitos da Teoria Social de Pierre Bourdieu. DataGramaZero, Rio de Janeiro, v.5, n.5, out. 2004. Disponível em: <www.dgz.org.br/out04/Art_05.htm〉.

Acesso em: 13 nov. 2017.

NEGRAS são maiores vítimas de homicídio de mulheres no país. Portal Brasil, 30 out. 2015. Disponível em:<http://www.brasil.gov.br/defesa-eseguranca/2015/11/mulheres-negras-saomais-assassinadas-com-violencia-no-brasil>. Acesso em: 12 nov. 2017.

ODALIA, N. O.O que é violência. 6. ed. São Paulo: Brasiliense, 1991.

OLINTO, Gilda. A inclusão das mulheres nas carreiras de ciência e tecnologia no Brasil. Inclusão Social, Brasília, v. 5, n. 1, 2011.
PANORAMA da violência contra mulheres no Brasil: indicadores nacionais e estaduais. Brasília: Senado Federal, 2016. Disponível em:<http://www.senado.gov.br/institucional/d atasenado/omv/indicadores/relatorios/BR.pdf>. Acesso em: 12 nov. 2017.

SAFFIOTI, H. I. B. Violência de gênero: lugar da práxis na construção da subjetividade. Lutas Sociais, São Paulo, n. 2, p. 59-79, 1997.

SANTOS, Y. G. A implementação dos órgãos governamentais de gênero no Brasil e o papel do movimento feminista: o caso do Conselho Estadual da Condição Feminina de São Paulo. Cadernos Pagu, Campinas, n. 27, jul/dez. 2006.

SARDENBERG, C. M. B. Educação escolar um instrumental importante para $O$ empedramento de mulheres?In: SEMINÁRIO INTERNACIONAL: TRILHAS DO EMPODERAMENTO DE MULHERES, 1., 2006, Salvador. Anais... Salvador: NEIM/UFBA, 2006.

SCOTT, J. W. Gênero: uma categoria útil para a análise histórica. Educação \& Sociedade, Porto Alegre, v.16, 1990, p. 5-22.

SILVA, L. L.; COELHO, E. B. S. CAPONI, S. N. C. Violência silenciosa: violência psicológica como condição da violência física doméstica. Interface: comunicação, saúde, educação, Florianópolis, v. 11, n. 21, p. 93103, jan./abr. 2007.

SILVEIRA, L. P. Serviços de atendimento a mulheres vítimas de violência. In: DINIZ, S. G; SILVEIRA, P. L.; MIRIN, L. A. L. (Orgs.). Vinte e cinco anos de respostas brasileiras em violência contra a mulher: alcances e limites. São Paulo: Coletivo Feminista Sexualidade e Saúde, 2006, p. 45-77.

SOUZA, Maria da Paixão Neres. Abordagem inter e transdisciplinar em ciência da informação. In: TOUTAIN, L. M. B. B. (Org.). Para entender a ciência da informação. Salvador: EDUFBA, 2007. p. 75-90.

TARGINO, Maria das Graças. Biblioteconomia, Informação e Cidadania. Revista da Escola de Biblioteconomia da UFMG, Belo Horizonte, v. 20, n. 2, p. 149160, jul./dez. 1991. 
TELES, M. A. A; MELO, M. O que é violência contra a mulher. São Paulo: Brasiliense, 2003.

WAISELFIZ, J. J. Mapa da violência 2013: Homicídio e Juventude no Brasil. Brasília: Flacso, 2013. Disponível em :< http://www.mapadaviolencia.org.br/pdf2013/mapa2013_homicidios_juventude.pdf>. Acesso em: 13 nov. 2017.

WAISELFIZ, J. J. Mapa da violência 2015: Homicídio de Mulheres no Brasil. Brasília: Flacso, 2015. Disponível em: <http://www.mapadaviolencia.org.br/pdf2015 /MapaViolencia_2015_mulheres.pdf>. Acesso em: 13 nov. 2017.

WERNECK, J.; NILZA, I. (Coord.) A situação dos direitos humanos das mulheres negras no Brasil: violência e violações. São Paulo: Geledés; Rio de Janeiro: Criola, 2016. Disponível em: $<$ https://www.geledes.org.br/wp-content/uploads/2016/11/Dossie-MulheresNegras-PT-WEB3.pdf>. Acesso em: 13 nov. 2017.

\section{AGRADECIMENTOS}

Por fim, gostaríamos de reiterar nossos agradecimentos à Secretaria Estadual da Mulher e da Diversidade Humana do Estado da Paraíba e do Centro Estadual de Referência da Mulher Fátima Lopes pelo acolhimento e parceria na realização desta pesquisa. 